\title{
Optical band gap and photoluminescence studies of Eu3+-doped zinc silicate derived from waste rice husks
}

\begin{abstract}
In this study, investigation on photoluminescence and optical properties of europium doped zinc silicate ( $\mathrm{Zn} 2 \mathrm{SiO} 4: \mathrm{Eu} 3+)$ glass ceramics derived from white rice husk ash as potential silica source have been done. Undoped and $3 \mathrm{wt}$. \% of europium doped zinc silicate were prepared by solid state method and sintered at $600-1000{ }^{\circ} \mathrm{C}$ for $2 \mathrm{~h}$. XRD analysis revealed the phase formation of amorphous, $\alpha$ or $\beta-\mathrm{Zn} 2 \mathrm{SiO} 4: \mathrm{Eu} 3+$ phases of the glass and glass ceramic samples. FESEM results show the samples were irregular in shapes but well connected and formed large grain crystallites as sintering temperatures increases. The optical band gap values for undoped samples are increasing from $2.97 \mathrm{eV}$ to $3.39 \mathrm{eV}$ respectively. Meanwhile, the optical band gap values for $3 \mathrm{wt}$. \% Eu3+ doped samples decrease from $4.14 \mathrm{eV}$ to $2.62 \mathrm{eV}$ and increase again to $3.71 \mathrm{eV}$ as sintering temperature increases. PL analysis concludes that the red emission exhibited corresponding to 5D0 $\rightarrow 7 \mathrm{~F} 2$ electron configuration at $612 \mathrm{~nm}$ while excitation spectra was found at $400 \mathrm{~nm}$ attributed to 7F0 $\rightarrow$ 5L6 transition. As conclusion, Eu3+ doped $\mathrm{Zn} 2 \mathrm{SiO} 4$ glasses has potential as glass host phosphor which can be used for optical devices such as plasma display panels (PDPs) and cathode ray tubes.
\end{abstract}

Keyword: Zinc silicate; Europium; Rice husk; Optical properties; Solid state 